\section{Myasis occuring in a neonate}

\author{
Temitope O. Obasa, \\ Funmilola Olusola Sowunmi
}

Neonatal Intensive Care Unit, University of Ilorin Teaching Hospital, Ilorin, Nigeria

\section{Abstract}

Myasis is the infestation of skin by larvae or maggots of a variety of flies. It is a condition that occurs more commonly in adults who are living and/or have visited tropical countries. It rarely occurs in neonates, and even when seen, only few larvae are extracted. This case report describes myasis occurring in an 11day-old female who had 47 larvae in her skin.

\section{Case Report}

M.M. is an 11-day-old female who presented at Neonatal Intensive Care Unit with a 7-day history of a bilateral eye discharge, 6-day history of swellings on the skin over the abdomen and 1-day history of fever. Eye discharge initially started in the left eye, but later spread to both eyes. There was no cough or difficulty breathing. Skin swellings were initially noticed over the abdomen, but later spread to involve the upper thigh, back and buttocks. The lesions were firm and small in size, non appeared to be fluid filled. They did not appear to increase in size or quantity. Mother did not have any genital lesions prior to delivery, and had apparently never been treated for any sexually transmitted disease. The family lived in a two room apartment surrounded by bushes. The infants' clothes were usually spread over grass after they had been laundered. They were never ironed. Fever was moderate grade, but with no irritability or abnormal body movements. She had been placed on paracetamol syrup since onset of the illness, with no improvement. Baby was on breast milk and water, and had received $\mathrm{BCG}, \mathrm{OPV}^{\circ}$ and Hepatitis B vaccines. Mother commenced ANC, at a private hospital, at about her $3^{\text {rd }}$ month of gestation and this was regularly attended. The baby was delivered at term, and there was no history to suggest asphyxia at birth.

Examination revealed a conscious female who was pink in room air, anicteric, hydrated, febrile at $38.3^{\circ} \mathrm{C}$ and appropriate for gestational age. She had a bilateral purulent eye discharge, with periorbital erythema. There were multiple papular lesions over her lower abdomen, thighs, back and buttocks; in all 47 of such lesions were present (Figure 1). They measured between 4-15 $\mathrm{mm}$ in diameter, the skin surrounding the larger lesions was minimally erythematous. They felt firm and did not break. Systemic examination did not reveal any abnormal findings. An initial assessment of Bullous Impetigo with a background late onset sepsis was made. Samples for a CBC and blood culture were drawn, and she was commenced on IV Amoxicillin + Clavulanic acid and IM Gentamycin, the lesions were painted with gentian violet. Investigation results are as shown in Table I.

A complete blood count showed a normal haematocrit of $41 \%$, leucocytosis with a WBC count of $29 \times 109 / \mathrm{L}$ of which $92 \%$ were polymorphonuclear cells, 6\% lymphocytes and 2\% monocytes. Platlet count was normal at $393 \times$ 109/L. Electrolyte profile revealed hyponatremia $(128 \mathrm{mmol} / \mathrm{L})$ but, potassium urea and creatinine levels were within acceptable limits. The eye swab culture yielded Pseudomonas aeruginosa, Klebsiella sp, and Staphylococcus aureus all sensitive to Gentamycin, ceftazidime and Augmentin. The blood culture did not yield any growth. On the 3 rd day on admission, while the nurses were in the process of painting the lesions, what were initially thought to be maggots were found on the baby's cot and clothing. On closer inspection, it was discovered that these larvae emanated from the lesions on the baby's back. Attempts were made to extract the remaining larvae from the unruptured papules, but the process was discovered to be uncomfortable for the patient. Additionally, given the vast number of lesions (47 in all), the procedure was aborted. Figure 2 shows a larva in the process of exiting a papule. At this time, the diagnosis was changed to Cutaneous Myasis, and the lesions were covered with camphorated petroleum jelly. ${ }^{1}$ Attempts to identify the specific species responsible proved abortive. Within the space of the next 24-36 hours, dead larvae were teased out of most of the lesions, and baby was discharged home on the 7th day. On follow up, all the lesions had dried up and there was little evidence of any prior occurrence.

\section{Results and Discussion}

Myiasis is an infestation of the skin by developing larvae (maggots) of a variety of fly species (myia is Greek for fly) within the arthropod order Diptera. Worldwide, the most common flies that cause the human infestation are: i) Dermatobia hominis (human botfly), which is endemic to tropical Mexico, South America, Central America and Trinidad; and ii) Cordylobia anthropophaga (tumbu fly), which is endemic to Sub-Saharan Africa. ${ }^{2}$

Based on the site of infestation myiasis can be classified as i) Cutaneous Myiasis, of wich there are 2 clinical types a) Wound myiasis
Correspondence: Temitope 0. Obasa, Department of Paediatrics, University of Ilorin Teaching Hospital, Ilorin, Kwara State, Nigeria.

Tel. +23.48034988894

E-mail: drtopeobasa@gmail.com

Key words: neonate, myasis, botfly, tumbu fly.

Acknowledgements: we are grateful to the mother of this neonate who graciously gave her permission to allow us publish this report.

Contributions: FOS was responsible for summarising the case from admission, discharge and through till follow up; T00 was responsible for the literature review and compilation of this report.

Conflict of interests: the authors report no conflict of interests.

Received for publication: 11 September 2012. Revision received: 4 0ctober 2012.

Accepted for publication: 23 October 2012.

This work is licensed under a Creative Commons Attribution NonCommercial 3.0 License (CC BYNC 3.0).

(C) Copyright T.O. Obasa and F.O. Sowunmi, 2012

Licensee PAGEPress, Italy

Pediatric Reports 2012; 4:e34

doi:10.4081/pr.2012.e34

(caused by Cochliomyia Americana and Chrysomyia bezziana) and b) Furuncular myiasis (caused by the human botfly and tumbu fly infestation), ii) Nasopharyngeal-myiasis (nose, sinuses and pharynx are involved), iii) Opthalmo-myiasis which affects eyes, orbits and periorbital tissues (caused by Oestrus ovis (sheep botfly) and iv) Intestinal-myiasis and urinal-myiasis (involves invasion of alimentary tract or urogential system [caused by Hypoderma bovis (infested cattle) and Gasterophilus intestinalis (infested horses) ].1,3,4 In the human botfly infestation, the female (which resembles a bee) egg-bearing fly attaches her eggs to the abdomen of a blood-sucking arthropod (a means of transportation known as phoresy), usually a mosquito. When the mosquito takes a blood meal from a warm-blooded animal, the local heat induces the eggs to hatch and drop onto the skin of the host, and enter painlessly through the bite of the carrier or some other small trauma. Once deposited in the skin, the larvae continue to develop, and can reach lengths of $15-20 \mathrm{~mm}$. In about 6-7 weeks, if the life cycle is undisturbed, they drop to the ground and pupate to form flies in 2-3 weeks.

In the tumbu fly infestation, the adult female is attracted by the odour of urine and faeces. The females lay their eggs on dry, sandy soil or on clothing. The eggs hatch in 1-3 days and can 
survive near the soil surface or on clothes for up to 2 weeks waiting for contact with a suitable host. Activated by heat, such as the body heat of the potential host, they are capable of penetrating the unbroken skin. They become fusiform to ovoid and reach a length of $13-15 \mathrm{~mm}$. Their larval stage is shorter than that of the human botfly and is completed in 9-14 days. While myiasis from the tumbu fly occurs on the trunk, thigh, and buttocks, botfly lesions are on the exposed areas of the body, including the scalp, face, fore-

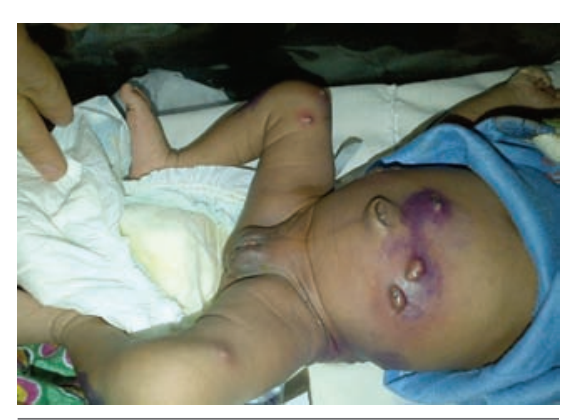

Figure 1. Furruncles on anterior abdominal wall and thighs.

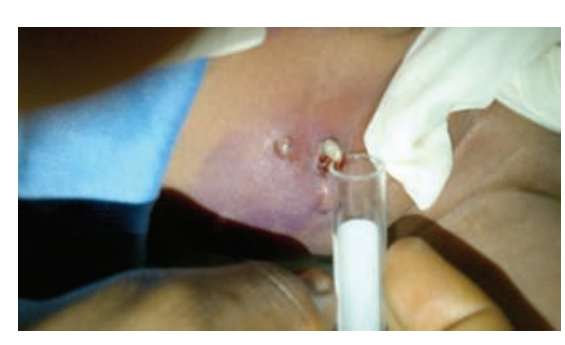

Figure 2. Larva extruding from one of the furruncles. arms, and legs. A pruritic erythematous papule develops within 24 hours of penetration, enlarging to $1-3 \mathrm{~cm}$ in diameter and almost $1 \mathrm{~cm}$ in height. These lesions can be painful and tender. Each has a central punctum from which serosanguineous fluid may be discharged. Lesions may become purulent and crusted. The tip of the larva may protrude from the central opening (punctum), or bubbles produced by its respiration may be seen. The inflammatory reaction around the lesions may be accompanied by lymphangitis and regional lymphadenopathy.

\section{Conclusions}

Myasis is commoner in the poorer, unsanitary tropical environment, which have conditions favourable to the breeding of the flies. It has been reported repeatedly in adults either living in an endemic environment, ${ }^{5}$ or who have just returned from a visit to endemic environments. ${ }^{6}$ It is believed to be rare amongst the newborn population, as usually these neonates are almost completely covered up, with only their faces exposed, and are not left unattended or outdoors. Contact with the fly (human botfly/tumbu fly) is thought to almost never occur. There is however documentation of maggots retrieved from the aural cavity, ${ }^{7}$ eyes and ears, ${ }^{8}$ and umbilical cord of neonates. ${ }^{9}$ This baby was presented because of the number of lesions, and because of the fact that this is the first ever case documented in this Teaching Hospital.

\section{References}

1. Bot flies, aka Torsalo or Dermatobia hominis. Available from: http://ambergriscaye.com/pages/town/botfly.html. Accessed on 11th September 2012.

2. Grammatikopoulou E. Myasis. Medscape Reference. Available atfrom http://emedicine.medscape.com/article/1491170overview. Accessed on 11th September 2012.

3. Bolognia JL, Jorizzo JL, Rapini R. Cutaneous myiasis. Dermatology 2008; 1300 01.

4. Burns T, Breathnach S, Cox N, Griffiths C. Diseases caused by arthropod and other noxious animals. In: Rook's textbook of dermatology. Vol 2. 7 ed. Malden, MA: Blackwell Publishing; 2004.

5. Sivakumar, Thangaswamy V, Sivaraj. Myasis of upper lip. JIADS 2010;1:38-40.

6. Weekes $\mathrm{M}$, Matheson $\mathrm{N}$, Coogle $\mathrm{S}$, Gkrania-Klotsas E. Furuncular myasis. BMJ Case Rep 2009;2009:bcr06.2009.2026.

7. Ahmed NW, Ismail A, Jeffery J, et al. Aural myasis in a neonat in peninsular Malasia. Parasit Vectors. 2009;2:63.

8. Cetinkaya M, Oxkan H, Koksal N, et al. Neonatal myasis: a case report. Turk J Pediatr 2008;50:581-4.

9. Duro EA, Mariluis JC, Mulieri PR. Umbilical myasis in a human newborn. Journal of Perinatology 2007;27:250-1. 